\title{
KELOMPOK 2
}

Universitas Bina Sarana Informatika Margonda

Jurusan : teknologi informasi Kata kuliah : 700-statistika Kelas : $17.3 \mathrm{~b} .01$
Monica Dhea Kirana-17190239

M. Ramzi Ramadhan- 17190342 Lukman al fajri- 17190365 Dimas kumara-17190374

Dosen: rde $-r$ deasy mandasari, $m . t$ 


\section{Ukuran Penyebaran Data (Kemiringan,Keruncingan)}

(STUDI KASUS : Penyebaran wabah covid-19 di beberapa kecamatan depok pada tanggal 28/9/2020) 


\section{Pengertian Kemiringan Data}

merupakan derajat atau ukuran dari ketidaksimetrisan (asimetri) suatu distribusi data.

Kemiringan data ada 3 jenis=

*simetris : menunjukkan letak nilai rata-rata hitung,median, dan modus berhimpit (berkisar di satu titik)

*miring ke kanan: mempunyai nilai modus paling kecil dan rata-rata hitung paling besar

*miring ke kiri : mempunyai nilai modus paling besar dan rata-rata hitung paling kecil 


\title{
Rumus Menghitung Derajat Kemiringan Dengan Pearson
}
$\circ \propto=\quad \bar{X}-\operatorname{Mod}$
$\propto=0$ maka datanya simetri
S
$\propto<0$ maka datanya miring ke kiri
$\propto>0$ maka dataya miring ke kanan

\author{
ATAU \\ $\circ \propto=\quad 3(\bar{X}-$ Med $)$ \\ S
}




\section{Contoh Soal Kemiringan}

Tentukan derajat kemiringan menurut rumus pearson dari data tersebut $=$

$4,5,3,2,2,10,6,8$

Jawab=

Data terurut=2,2,3,4,5,6,8,10. Maka diperoleh

$$
\overline{\mathrm{X}}=\frac{1}{\mathrm{n}} \sum x=\frac{1}{8(2+2 \ldots+10)}=5
$$

Median $=$ med $=1 / 2(4+5)=4,5$

Modus $=$ mod $=2$ 


\section{Rumus Blowley}

$\alpha=\underline{Q 3}+\underline{Q 1}-\underline{Q 2}$

Q3-Q1

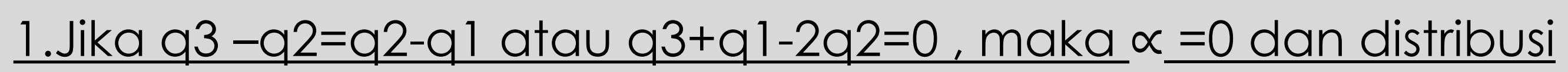
datanya simetri

2. Jika $q 1=q 2$, maka $\propto=1$ dan distribusi datanya miring ke kanan

3.Jika $\mathrm{q} 2=\mathrm{q} 3$ maka $\propto=-1$ dan distribusi datanya miring ke kiri 


\section{Distribusi Simetrik}

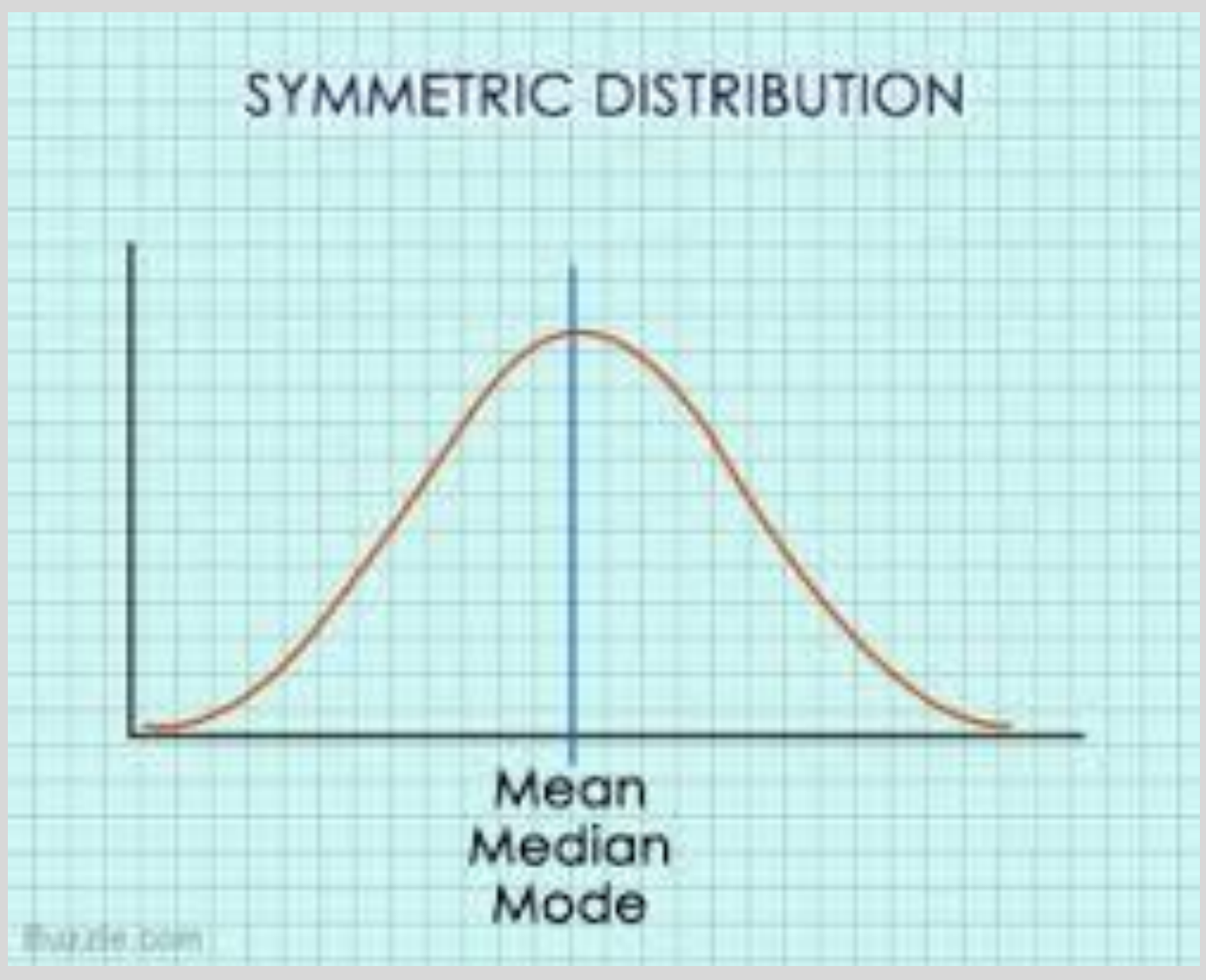




\section{Distribusi Positif}

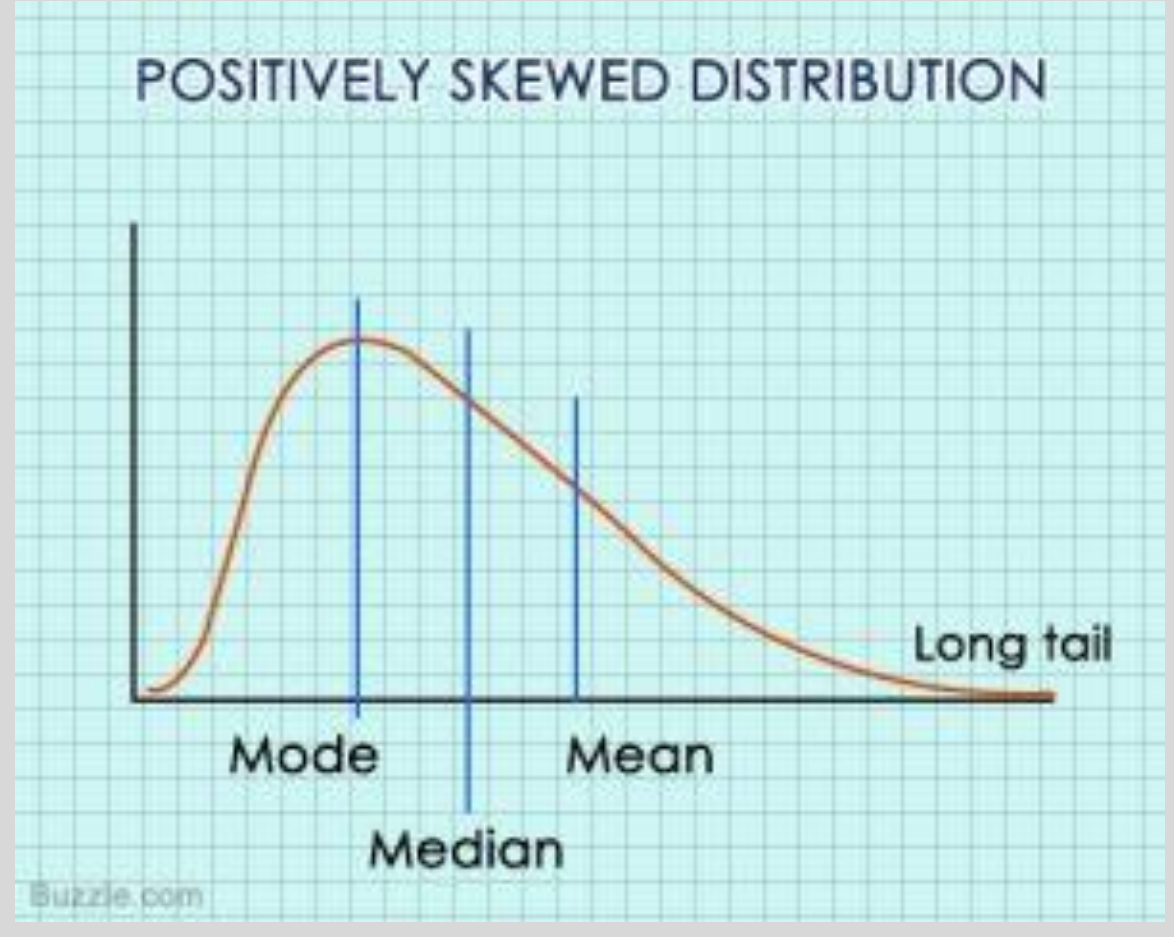




\section{Distribusi Negatif}

\section{NEGATIVELY SKEWED DISTRIBUTION}

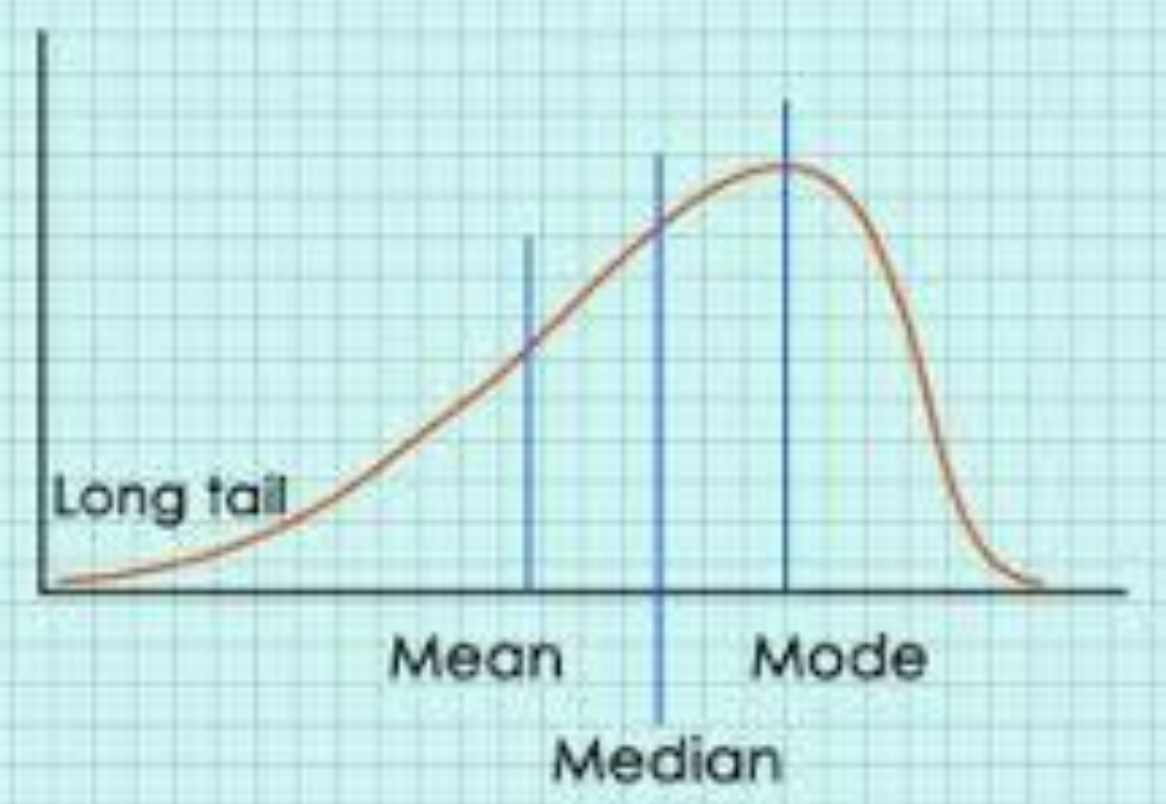




\section{Ukuran Kemiringan Kurva}

- Rata-rata dan varians sebenarnya merupakan hal istimewa dari kelompok ukuran lain yang disebut momen

- Momen juga dapat digunakan sebagai cara untuk mengukur ketidaksimetrisan terhadap distribusi data dalam suatu variabel 


\section{Pengertian Keruncingan Distribusi Data}

- Merupakan derajat atau ukuran tinggi rendahnya puncak suatu distribusi data terhadap distribusi normalnya data. Keruncingan distribusi data ini disebut juga kurtosis. Ada tiga jenis derajat keruncingan, yaitu :

a. Leptokurtis : distribusi data yang puncaknya relatif tinggi

b. Mesokurtis : distribusi data yang puncaknya normal

c. Platikurtis : distribusi data yang puncaknya terlalu rendah dan terlalu mendatar 


\section{Contoh grafik}

\section{Grafik Derajat Keruncingan Distribusi Data}

f Leptokurtis f Mesokurtis f Platikurtis
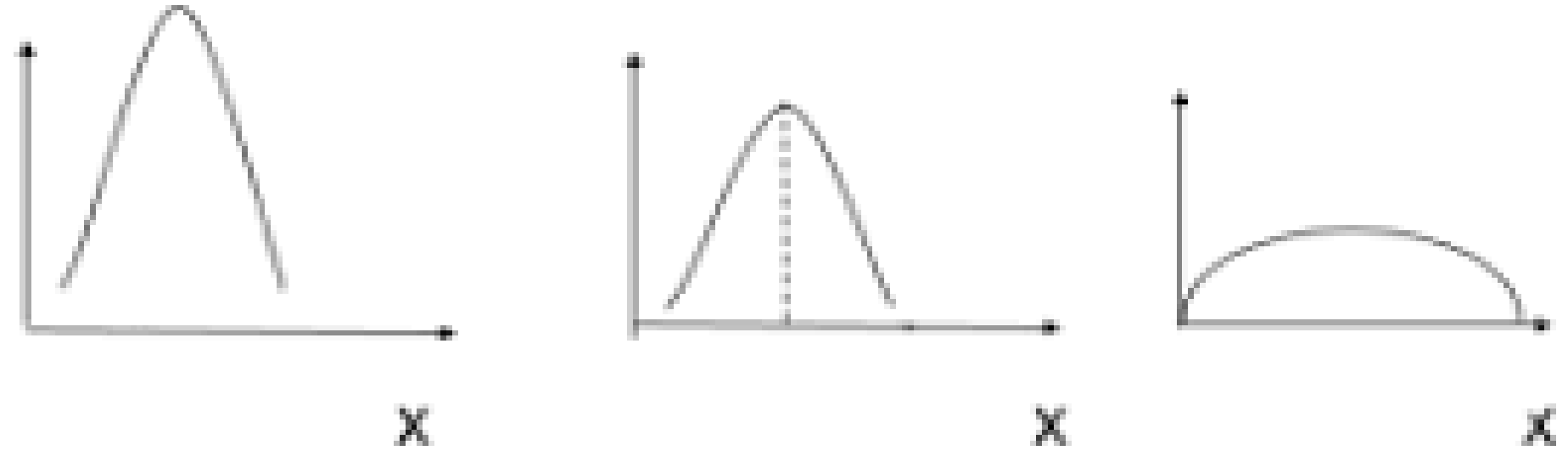


\section{Derajat keruncingan distribusi data $\propto$ 4 dapat dihitung berdasarkan rumus berikut}

$\Rightarrow$ Data tidak berkelompok

$$
\begin{aligned}
& a_{4}=\frac{1}{n s^{4}} \sum\left(X_{i}-\bar{X}\right)^{4} \\
& a_{4}=\frac{1}{n S^{4}} \sum f_{i}\left(M_{i}-\bar{X}\right)^{4}
\end{aligned}
$$

Keterangan :

$\checkmark \quad a_{4}=$ Derajat keruncingan

$\checkmark \quad X_{i}=$ Nilai data ke - i

Nilai rata-rata hitung

$\checkmark f_{i}=$ Frekuensi kelas ke - i

$\checkmark M_{i}=$ Nilai titik tengah kelas ke -i

$\checkmark \mathrm{S}=$ Simpangan baku

$\checkmark \mathbf{n}=$ Banyaknya data

Jika $a_{4}=3$ distribusi keruncingan data disebut mesokurtis

$a_{4}>3$ distribusi keruncingan data disebut leptokurtis

$a_{4}<3$ distribusi keruncingan data disebut platikurtis 
Data Pasien Corona yang meninggal dunia dan Sembuh di beberapa kecamatan depok pada tanggal (28/9/2020)

\begin{tabular}{|c|l|r|r|}
3 & Kecamatan & wafat & Sembuh \\
\hline 4 & Sukmajaya & 22 & 380 \\
\hline 5 & Pancoran mas & 17 & 328 \\
6 & Cimangis & 24 & 452 \\
\hline 7 & Beji & 14 & 281 \\
\hline 8 & Cilodong & 5 & 209 \\
\hline 9 & Sawangan & 8 & 181 \\
\hline 10 & Tapos & 12 & 274 \\
11 & Bojong Sari & 8 & 158 \\
12 & Cipayung & 3 & 199 \\
\hline 13 & Cinere & 7 & 127 \\
\hline 14 & Limo & 10 & 153 \\
\cline { 2 - 4 } & & & \\
\end{tabular}


Hasil penghitungan skewness dan kurtosis

- Di aplikasi excel

- Column 1 merpakan hasil skewness dan kurtosis dari pasien yang wafat

- Column 1 merpakan hasil skewness dan kurtosis dari pasien yang sembuh

\begin{tabular}{|c|c|c|c|}
\hline Column 1 & & Columnz & \\
\hline Mean & 11,81818182 & Mean & 249,2727273 \\
\hline Standard Error & 2,053016326 & Standard Error & 31,24160714 \\
\hline Median & 10 & Median & 209 \\
\hline Mode & 8 & Mode & $\# N / A$ \\
\hline Standard Deviation & 6,80908484 & Standard Deviati & 103,6166887 \\
\hline Sample Variance & 46,36363636 & Sample Variance & 10736,41818 \\
\hline Kurtosis & $-0,52528489$ & Kurtosis & $-0,301052496$ \\
\hline Skewness & 0,689505575 & Skewness & 0,781090379 \\
\hline Range & 21 & Range & 325 \\
\hline Minimum & 3 & Minimum & 127 \\
\hline Maximum & 24 & Maximum & 452 \\
\hline Surn & 130 & Surn & 2742 \\
\hline Count & 11 & Count & 11 \\
\hline
\end{tabular}




\section{Hasil histogram dari aplikasi excel}

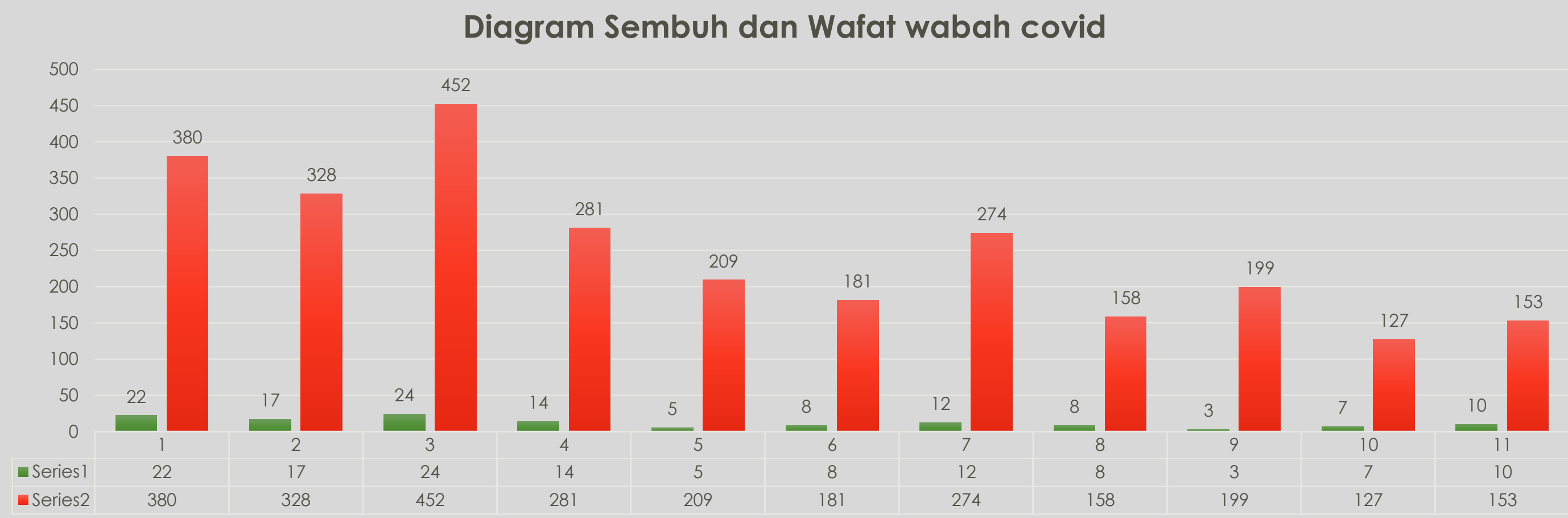




\section{Hasil output dengan aplikasi spss dengan data yang sama}

th output kelompok 2.spv [Document2] - IBM SPSS Statistics Viewer

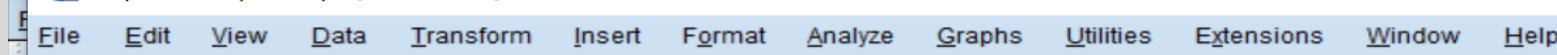

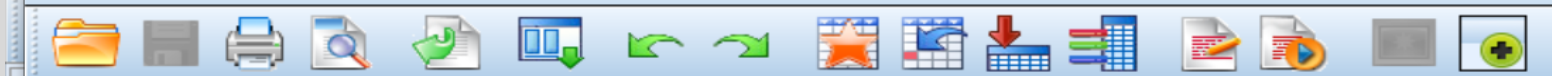

\section{曰国 Output}

$\Leftrightarrow \rightarrow$ 盏 Frequencies

䁌 Totes

Active Dataset

角 Statistics

国 Frequency Table

. Title

渑 sembuh

훙 Histogram

曾 Title

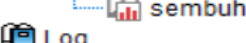

\begin{tabular}{|c|c|c|c|}
\hline \multicolumn{4}{|c|}{ Statistics } \\
\hline & & wafat & sembuh \\
\hline \multirow[t]{2}{*}{$\mathrm{N}$} & Valid & 10 & 10 \\
\hline & Missing & 1 & 1 \\
\hline \multicolumn{2}{|l|}{ Mean } & 12.30 & 253.30 \\
\hline \multicolumn{2}{|c|}{ Std. Error of Mean } & 2.206 & 34.251 \\
\hline \multicolumn{2}{|l|}{ Median } & 11.00 & 236.50 \\
\hline \multicolumn{2}{|l|}{ Mode } & 8 & $127^{\mathrm{a}}$ \\
\hline \multicolumn{2}{|c|}{ Std. Deviation } & 6.977 & 108.310 \\
\hline \multicolumn{2}{|l|}{ Variance } & 48.678 & 11731.122 \\
\hline \multicolumn{2}{|l|}{ Skewness } & .515 & .645 \\
\hline \multicolumn{2}{|c|}{ Std. Error of Skewness } & 687 & .687 \\
\hline \multicolumn{2}{|l|}{ Kurtosis } & -.736 & -.656 \\
\hline \multicolumn{2}{|c|}{ Std. Error of Kurtosis } & 1.334 & 1.334 \\
\hline \multicolumn{2}{|l|}{ Range } & 21 & 325 \\
\hline \multicolumn{2}{|l|}{ Minimum } & 3 & 127 \\
\hline \multicolumn{2}{|l|}{ Maximum } & 24 & 452 \\
\hline \multicolumn{2}{|l|}{ Sum } & 123 & 2533 \\
\hline \multirow[t]{3}{*}{ Percentiles } & 25 & 7.25 & 156.75 \\
\hline & 50 & 11.00 & 236.50 \\
\hline & 75 & 18.25 & 341.00 \\
\hline
\end{tabular}

Multiple modes exist. The smallest value is 
Histogram dari data pasien yang sembuh dan wafat

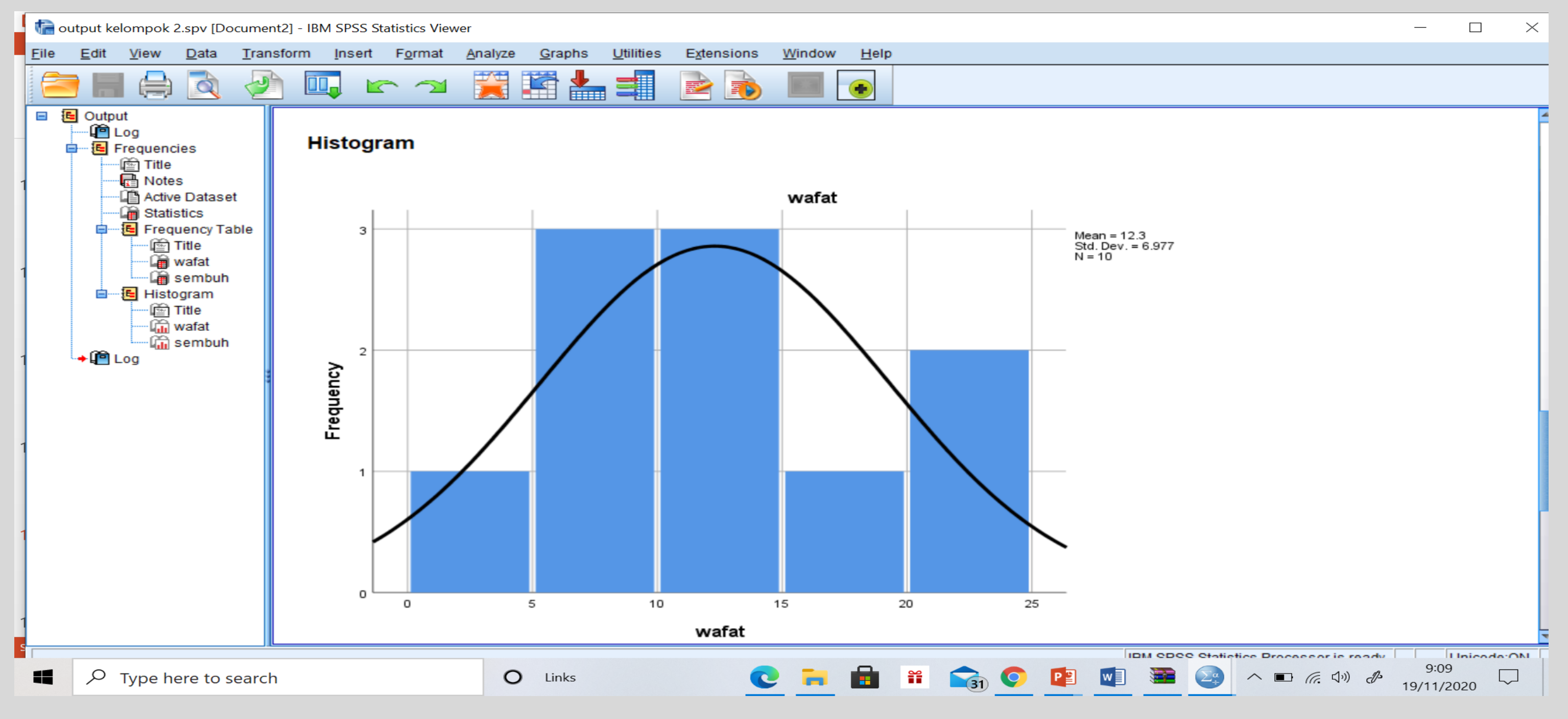


T. output kelompok 2.spv [Document2] - IBM SPSS Statistics Viewer

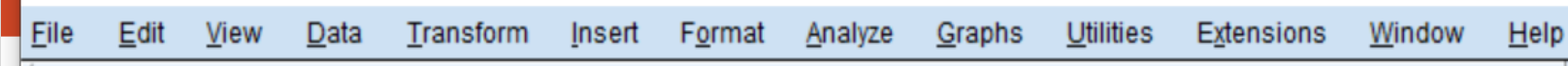

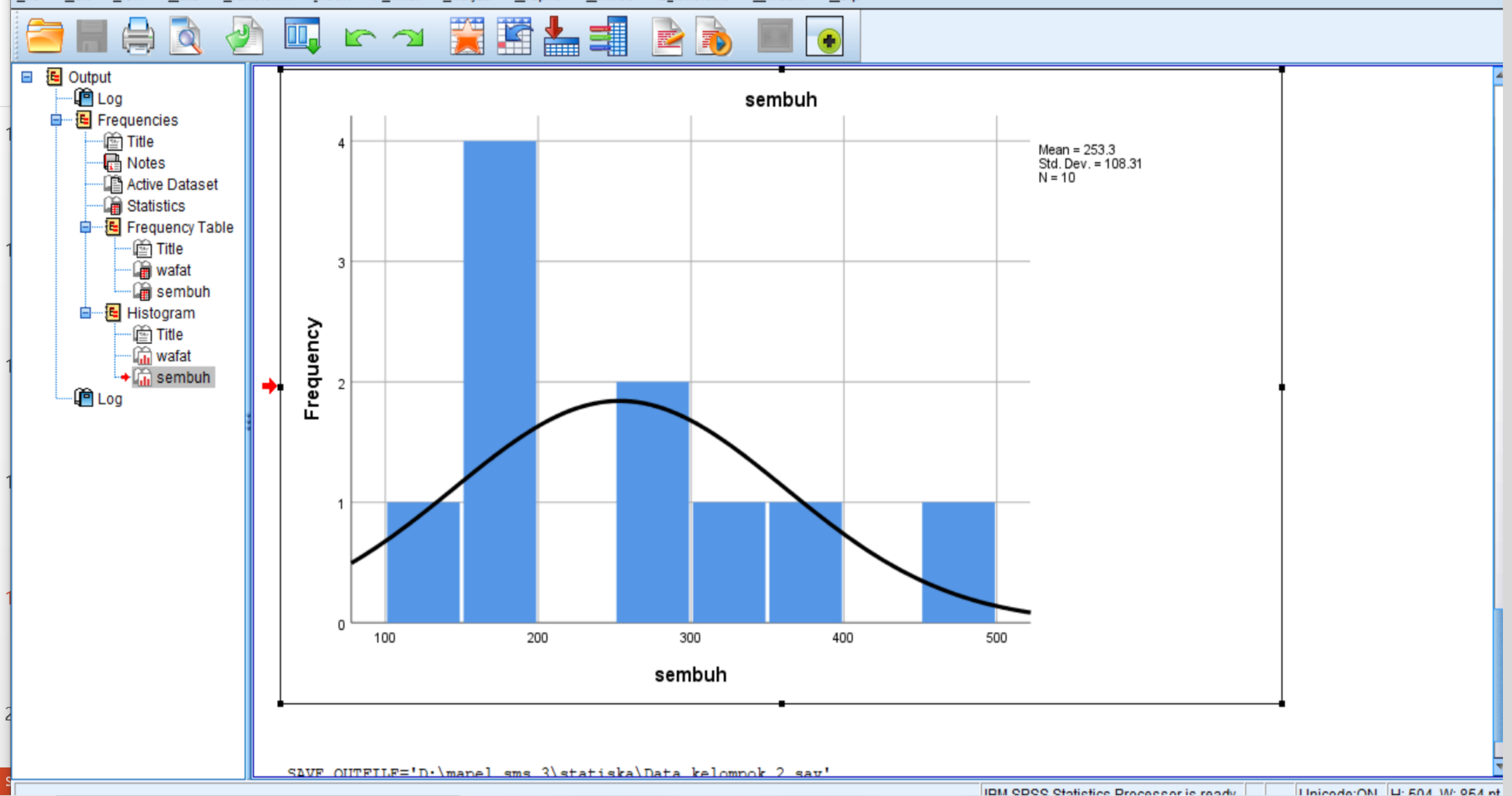

II $O$ Type here to search

L Links

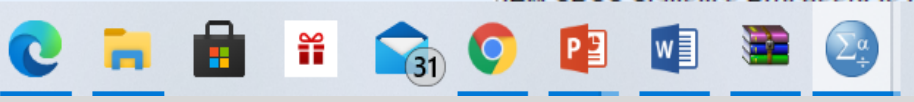




\section{-KESIMPULAN}

- Dari uraian makalah diatas dapat disimpulkan bahawa peran STATISTIKA sangat penting bagi kehidupan.Statistika sudah tidak asing lagi bagi kita khususnya (pengusaha/perkantoran) untuk memudahkan mendistribusikan data.Dan Statisika adalah teori yang dapat mempermudah cara kerja pendistribusian data yang telah berlalu maupun sampai data saat ini. 


\section{Daftar pustaka}

- https://www.sridianti.com/jenis-distribusi-miring-dan-contohnya.html

- https://www.slideshare.net/fatriaanggita/bab-6-staddas-ukurankeruncingan\#: : :text=suatu\%20distribusi\%20normal.,Kurva\%20platikurtik\%20adalah\%20kurva\%20yang\%20betuknya\%20mendatar\%20 dan\%20nilai\%2Dnilai,sampai\%20jauh\%20dari\%20rata\%2Dratanya

- https://www.google.com/search? $q=$ distribusi+simetris\&safe=strict\&rlz=1 C 1 GCEU enID851ID851\&sxsrf=ALeKKO0ZI

- https://www.greelane.com/id/sains-teknologi-matematika/matematika/what-iskurtosis-3126241/

- https://megapolitan.kompas.com/read/2020/09/28/18255031/sebaran-1200lebih-pasien-covid-19-di-depok-terbanyak-di-sukmajaya-dan?page=all

- Modul pertemuan 4 
Thank you for watching

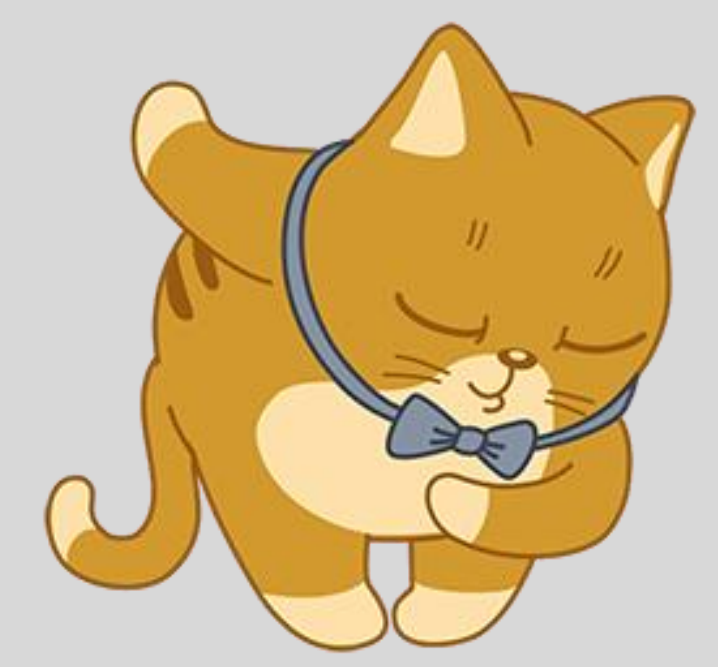

